Mariano Osuna, entre la realidad y la leyenda

Antonio Sánchez-González

Universidad de Huelva 



\title{
Mariano Osuna, entre la realidad y la leyenda
}

\section{Mariano Osuna, between reality and legend}

\author{
Antonio Sánchez-González \\ Universidad de Huelva \\ antonio.sanchez@dhis2.uhu.es
}

Fecha de recepción: 30 de mayo de 2018

Fecha de aceptación: 20 de enero de 2020

\section{Resumen}

Este trabajo rinde homenaje al noble que más dio de qué hablar en su tiempo, el XII Duque de Osuna Mariano Téllez-Girón y Beaufort-Spontin (18141882), sin duda el último vástago de la gran raza de Osuna. Esta casa nobiliaria precisamente alcanzaba su cenit en pleno siglo XIX, convirtiéndose en una de las más poderosas de Europa. Pero el inmenso patrimonio amasado durante generaciones que recibe Mariano sin esperarlo, al ser segundón de la Casa, se consume por completo, al gastar el duque con tanto derroche que ni siquiera pudo pagarse el sepulcro donde yace. De ahí que Mariano Osuna haya pasado a la historia, por encima de todo, como arquetipo de despilfarrador. Sin embargo, también desbordaba humanidad y generosidad a raudales, de lo que recibieron sobradas muestras no solo sus deudos y dependientes sino también su propia patria pues jamás cobró los muchos servicios militares y diplomáticos que prestó a España.

Palabras clave: Téllez-Girón Beaufort, Mariano (1814-1882); Ducado de Osuna; ¿dilapidador o altruista?; Embajador extraordinario; Quiebra económica.

\footnotetext{
Abstract

This work pays homage to the most controversial noblemen of his time, the XII Duke of Osuna Mariano Téllez-Girón and Beaufort-Spontin (1814-1882); undoubtedly the last scion of the great breed of Osuna. This noble house precisely reached its zenith at the height of the 19th century becoming one of the most powerful houses all over Europe. However, the vast wealth gathered over generations that Mariano received unexpectedly, since he was the second son of the house, ran out because of the Duke's wasteful spending. He could not even afford the payment of his tomb
} 
where he lies. That is why Mariano Osuna has passed into history, above all, as the archetype of spendthrift. Anyway, he also overflowed humanity and generosity in abundance, as quite evidenced to his relatives, dependents and homeland. He never wanted to charge the emoluments of the many military and diplomatic services that he provided Spain with.

Keywords: Téllez-Girón Beaufort, Mariano (1814-1882); Duchy of Osuna; Wasteful or altruistic?; Ambassador extraordinary; Economic bankruptcy.

\section{INTRODUGGIÓN}

Resulta difícil dedicarse al estudio de la nobleza hispana y europea del siglo XIX sin tropezar con la figura del XII Duque de Osuna, Mariano Téllez-Girón y Beaufort-Spontin, sin duda, el último vástago de la gran raza de Osuna, iniciada por sus ascendientes más remotos allá por el siglo XI. Esta Casa nobiliaria alcanza su cenit por la agregación de numerosos e importantísimos estados y títulos incorporados con el tiempo, lo que la convirtió en una de las más poderosas de Europa en el siglo XIX, junto con la de Medinaceli.

Ese vasto patrimonio le llega al duque Mariano a costa de perder a la persona que más quiso, su único hermano -el primogénito- Pedro de Alcántara. Éste lo tenía todo: era culto, apuesto, favorito de las damas y, sin embargo, le persiguió el maleficio; Mariano, en cambio, aun siendo garboso, era rechoncho, calvo, miope..., y no había recibido la preparación ducal que se había dado a su hermano mayor, pero resultó ser un afortunado.

Un hermano se muere para que el otro viva, y de qué manera... No solo hereda Mariano Osuna la fortuna más grande de España sino que, además, resulta beneficiado por las medidas liberales de su tiempo que propiciaron la abolición de los mayorazgos. Esto es lo mismo que decir que todo ese increíble patrimonio, que recibió sin esperarlo, se convertía en bienes libres o, lo que es igual, que él podía disponer del mismo a su antojo. Y esa enorme riqueza la consume por completo en vida, a mayor esplendor y gloria de su nombre, gastando con tanto derroche que ni siquiera pudo pagarse el sepulcro donde yace. Hereda 5 millones de pesetas y, al morir, deja un pasivo de 40.

De ahí que el duque Mariano Téllez-Girón haya pasado a la historia, por encima de todo, como arquetipo de despilfarrador, dilapidador o manirroto, hasta el punto que durante décadas en Madrid y otras partes de España se solía decir, cuando alguien realizaba excesivos gastos, “¡Ni que fuera Osuna!”. Sólo se ponía sus lujosos trajes el día de su estreno, y se cambiaba de ropa varias veces al día. Las fiestas que organizaba se hicieron célebres tanto en Madrid como en París, Londres, Berlín o San Petersburgo. Precisamente en la corte rusa se dio a conocer con el título de "Grande de los Grandes de España", dignidad no oficial que él mismo inventó. 
Pero más allá de este rasgo con que ha pasado a la posteridad, que sin duda forma parte de su leyenda, Mariano Osuna desbordaba humanidad y generosidad pues tenía un gran corazón, de lo que recibieron sobradas muestras sus deudos y dependientes. Y también su propia patria, con la que fue tremendamente desprendido pues nunca quiso cobrar los emolumentos de los muchos servicios militares y diplomáticos que le prestó.

\section{ORIGEN Y EVOLUGIÓN DE LA GASA DE OSUNA HASTA EL SIGLO XIX}

Remontándonos a los orígenes, la Casa de Osuna es una rama desgajada de la familia Acuña y, como tal, desciende de los antiguos reyes de León ${ }^{1}$. El infante Pelayo Fruela, llamado "el Diácono" por haber recibido en su juventud órdenes sagradas, fue confirmado como príncipe de sangre real en 1032 y poseyó grandes heredamientos en Galicia y en tierras de Carrión. Le fue dispensada su condición eclesiástica al contraer matrimonio con Aldonza Ordóñez, hija del también infante Ordoño "el Ciego".

El tercero de los hijos del matrimonio, Pelayo Peláez, fue el progenitor de la Casa de Acuña. Descendiente directo suyo va a ser Rodrigo González "el de los jirones", poblador de Valladolid, conquistador de Toledo y rico-hombre de Alfonso VII. Es el héroe legendario de la batalla de Sagrajas -la Sagra- o Zalaca (1086) contra los moros, en la que salvó la vida a su soberano, reconocido por el manto que llevaba sobre los hombros y objeto de asedio del enemigo para prenderlo vivo, al cambiar con él su caballo y cubrirse con el manto real, que quedó hecho jirones; esta hazaña la perpetuó el propio monarca colocando en las armas de don Rodrigo tres jirones, y por éste, adoptando el mote o alcuña de "Girón" como apellido para sus sucesores.

Uno de ellos, Gonzalo Ruiz Girón, rico-hombre de Alfonso XI, que había asistido al sitio de Algeciras, casó con María Téllez de Meneses, señora de Villasís, conocida también por el sobrenombre familiar de "la Raposa" por las mañas y tretas en artes de guerra contra los moros que habían demostrado los Meneses. Por ella usaron sus hijos y muchos de sus sucesores el patronímico Téllez, que unido al apellido Girón han formado el nombre completo de este linaje hasta nuestros días.

En el mismo siglo XIV se extingue la línea masculina de los primeros Girón y la heredera, Teresa Téllez Girón, llevó en 1398 la sangre y representación del linaje

1 Sobre los orígenes y evolución de la Casa de Osuna puede consultarse los clásicos nobiliarios de Salazar y Castro (1697), Francisco Fernández de Bethencourt (1908), los hermanos García Carraffa (1921) y Julio de Atienza (1948). Pero el estudio más importante de esta Casa es el realizado por Ignacio Atienza (1987), basado fundamentalmente en la consulta de los fondos que hoy se conservan en el Archivo de la Nobleza Española en Toledo, sección "Osuna". 
a la familia Acuña por su matrimonio con el conde de Valencia Martín Vázquez de Acuña. De este enlace nacería Alfonso Téllez Girón, que sucedió en el mayorazgo con el apellido materno, continuando así la representación de la Casa; casado con la señora de Belmonte, María Pacheco, ambos fueron padres de aquellos dos maestres de quien Jorge Manrique dijo en sus célebres Coplas que eran "prosperados como reyes": el primogénito, Juan, apellidado Pacheco de conformidad con los capítulos matrimoniales de sus padres, fue el célebre Marqués de Villena, valido del monarca castellano Enrique IV y maestre de la orden de Santiago; por su parte, el segundogénito, Pedro, conservó el apellido paterno de Téllez-Girón, y fue camarero mayor del monarca, maestre de Calatrava y notario mayor de Castilla y León. Éste destacó heroicamente en las campañas contra los moros en Andalucía y, entre otros muchos señoríos, ostentó el de la villa de Osuna, que había permutado en 1464 con la propia orden de Calatrava, por las de Bélmez y Fuenteovejuna. Con un importante patrimonio que, además de Osuna, comprendía las villas de Gumiel de Izán, Santibáñez, Ureña, Peñafiel, Briones, Frechilla, Villafrechós, Ortegícar, Villamayor, Morón, Arahal, Gelves, Olvera y Archidona, más la fortaleza de Cazalla, Pedro Téllez-Girón instituyó a mediados del siglo XV el mayorazgo de Ureña, de rigurosa agnación masculina (es decir, solo podía recaer en los varones de varones).

Este mayorazgo obtendría en 1464 la dignidad condal con el título de Ureña por merced de los Reyes Católicos y, en 1562, pasaría a la dignidad ducal con título de Osuna por concesión de Felipe II, al ser esta villa sevillana la cabecera del estado.

Hablar de los condes de Ureña en el siglo XVI nos lleva a recordar la figura de aquel que se le conoció con el sobrenombre de "Padre de los pobres", Juan Téllez-Girón, apodado "el Santo", fundador de la iglesia mayor de Osuna -que bajo su protección se convirtió en colegial-, de su antigua Universidad, además de 16 conventos y numerosas obras pías en sus dominios. Su primogénito y heredero, el quinto Conde de Ureña Pedro Téllez Girón, fue el agraciado con el nombramiento de primer Duque de Osuna.

Y hablar de los duques de Osuna igualmente nos obliga a rememorar la existencia de aquel tercer Duque, Pedro Téllez-Girón, conocido como "el Gran Duque", que fuera Virrey de Sicilia y Nápoles, protector y gran amigo de Quevedo, que tanto destacó como estratega naval y como político, aunque recibiera un injusto trato al final de sus días (muere en prisión tras ser acusado de dilapidador del tesoro real y de traidor por tratar con los turcos).

Durante el siglo XVII y la primera mitad del XVIII la Casa de Osuna seguirá representando altas distinciones a favor de la monarquía española. Uno de sus titulares, el sexto duque Francisco de Paula Téllez-Girón y Benavides, ostentará la representación del monarca Felipe V en los tratados de paz de Utrecht de 1713.

Pero, sin duda, el engrandecimiento de los Osuna se va a producir en el último tercio del siglo XVIII al entroncar su Casa con la de los Condes-Duques de Benavente, 
por el matrimonio que celebran en 1771 Pedro Téllez-Girón y Pacheco, IX Duque de Osuna, con su prima María Josefa Alonso Pimentel, XV Condesa y XII Duquesa de Benavente y otros títulos. Esta era "por su calidad, sus circunstancias y las muchas ilustres Casas que se reunieron en su persona, una de las más grandes señoras y la mayor heredera de su tiempo en toda España" (Fernández de Béthencourt, 1900, p. 600). También diría de ella el general Fernández de Córdova en sus Memorias que era "la más encopetada dama de España y de mayor elegancia y rango de Europa" (1886, I, p. 50).

Efectivamente así debió ser pues, aparte de su valía personal y su gran carácter -que tan bien queda reflejado en la biografía que de ella hizo la Condesa de Yebes, Carmen Muñoz de Figueroa (1955)- va a aportar a la Casa de Osuna su inconmensurable grandeza y patrimonio, proveniente de diversas vías:

- Como representante primogénita y última de los Pimentel era -como queda dicho- XV Condesa y XII Duquesa de Benavente, condesa de Mayorga, de Luna y Marquesa de Jabalquinto.

- Como representante primogénita de los Zúñiga era, además de XIII Duquesa de Béjar, Duquesa de Mandas y Villanueva, de Plasencia, Marquesa de Gibraleón y de Terranova, Condesa de Bañares y de Belalcázar y Vizcondesa de la Puebla de Alcocer.

- Como representante primogénita del famoso y esclarecido linaje de los Borja, era XIV Duquesa de Gandía, Marquesa de Lombay, Princesa de Squilache y de Anglona, Condesa de Oliva y de Mayalde, Duquesa de Monteagudo, Marquesa de Marguini, condesa de Osilo y Coguinas. Solamente el ducado de Gandía llevaba anejo 14 baronías y comprendía 60 villas y aldeas del reino de Valencia y otras 39 del de Cerdeña.

- Y como representante primogénita de los Ponce de León, era además XII Duquesa de Arcos, Marquesa de Zahara y Condesa de Bailén y de Casares.

Este matrimonio Osuna-Benavente tendría prolífica sucesión, pero el heredero de estas dos importantes casas no iba a ser el primogénito Francisco de Borja TellezGirón y Pimentel (que, al morir en vida de su madre, solo heredó la Casa de Osuna), sino que serían - por partida doble, sucesivamente- los dos hijos de las nupcias que éste contrajo en 1802 con la Condesa de Beaufort-Spontin y del Sacro Imperio Romano María Francisca de Beaufort y Toledo: el malogrado Pedro de Alcántara, y el afortunado Mariano.

\section{EL MALOGRADO XI DUQUE PEDRO}

Efectivamente el primogénito, Pedro de Alcántara Téllez-Girón y BeaufortSpontin (1810-1844), solo sería un paréntesis. Había nacido por azar en Cádiz, el 10 
de septiembre de 1810, y bautizado el mismo día amadrinado por su abuela paterna la Condesa-Duquesa de Benavente. Se trataba del "doncel" más gallardo de la época; el que por su donaire, sus títulos y su fortuna - ¿fortuna o, mejor, riqueza?- constituía probablemente el mejor partido de Europa. Fue muy dado desde su juventud a las letras y a las artes; tanto que, además de ser un buen esgrimidor y destrísimo jinete, prevaleció en él toda su vida la cultura sosegada del espíritu frente a los bélicos ardores en que se habían empleado tantos de sus antepasados y se iniciaba ya el segundón Mariano.

En 1820, cuando aún era un niño, Pedro de Alcántara sucede en la casa de Ureña-Osuna por fallecimiento de su padre, convirtiéndose en XV Conde de Ureña, XI Duque de Osuna y XII Marqués de Peñafiel. Más tarde, al morir en 1834 su anciana abuela doña María Josefa Pimentel, recibió el cuantioso patrimonio que los Pimentel habían adquirido en sus fusiones con los Zúñiga, los Borja y los Ponce de León, sucediendo además en las Casas de los Conde-duques de Benavente, Duques de Béjar, Gandía y Arcos (y en las muchas otras agregadas en cada una de ésas que enumeramos atrás).

Pero además, muerto su tío -hermano de su abuela materna-, el XIII duque del Infantado Pedro de Alcántara de Toledo y Salm-Salm Hurtado de Mendoza, sucedió en 1841 en sus títulos y honores que eran, junto con el ducado del Infantado, los marquesados de Santillana, Cenete y Argüeso, los condados del Real de Manzanares, Saldaña y del Cid, pero además se convertía en XI duque de Lerma, duque de Estremera y de Francavilla, marqués de Almenara, Algecilla y Cea, más príncipe de Éboli y de Mélito, aparte de XII marqués de Távara y conde de Villada.

Fue igualmente declarado sucesor legítimo en la antigua grandeza y en todos los derechos de los famosos Almirantes de Castilla, vacantes desde 1799, convirtiéndose por ello en XIII Duque de Medina de Rioseco y Conde Melgar. ¿Se podía ser más?

Pese a su patrimonio, el duque de Osuna don Pedro parece no advertir esa conjunción de grandezas que se le acumulan. Solo cree en su infortunio. De ahí que impresione una frase que escribe al final de su vida: "Con ser quien soy, jamás he conseguido nada que no haya tenido necesidad de solicitarlo". Así fue realmente.

Y un verdadero romántico, aun siendo el príncipe encantado de la corte, no podía tener final más desafortunado. Enamorado de una "mujer prohibida", esposa del Marqués de Alcañices, la muy bella Inés de Silva Téllez-Girón Walstein y Pimentel -por otro lado, prima carnal suya-, el duque de Osuna va a sufrir de una manera indescriptible, sufrimiento que le va a llevar a la muerte.

Pedro Osuna paseaba su soledad por su retiro madrileño de la Alameda -que había adquirido su abuela, la Condesa-duquesa de Benavente, para convertirlo en su "Capricho", que con este nombre se le conocía-. Y en una ocasión recibe allí la visita de su amor, que quiere disculparse por un malentendido que habían tenido en uno de los bailes a los que ambos asistían con asiduidad. Pedro de Alcántara paseaba en esos 
momentos su melancolía por el bosque de la Alameda y había dado órdenes oportunas de que no estaba para nadie. Tremenda equivocación pues solamente estaba para una persona, y esa persona era quien precisamente acababa de visitarle. Los criados le han dicho a la encantadora dama que no estaba el Sr. Duque, e Inés emprende viaje de vuelta a Madrid. A lo lejos, Osuna distingue un carruaje, el carruaje que retorna a su destino. Distinguió don Pedro la inconfundible presencia de la yeguada de Alcañices y corrió veloz tras su amor, tras la comitiva ya en marcha, cayendo entonces desplomado mientras llamaba a su amor imposible. Recogido y llevado a toda prisa a Madrid, el duque agoniza durante unos días, víctima de un infarto o paro cardíaco. Y el 25 de agosto de 1844, a los 33 años de edad, perdía la vida.

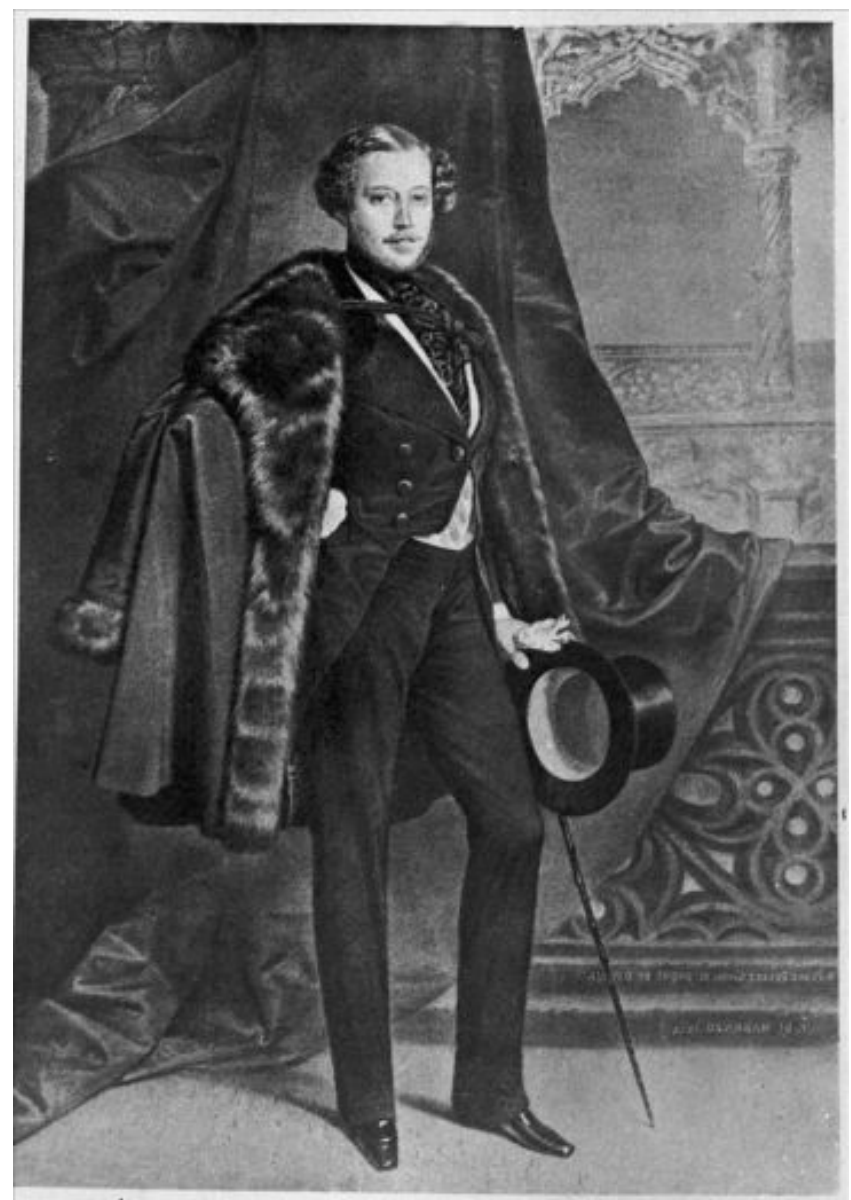

Figura 1. Pedro Téllez-Girón, XI Duque de Osuna, hermano mayor y único de Mariano

(Federico Madrazo. Banco de España. Madrid) 


\section{EL AFORTUNADO XII DUQUE MARIANO}

Mariano Téllez-Girón y Beaufort-Spontin había nacido segundogénito de los Duques de Osuna en la propia villa y corte de Madrid el 19 de julio de 1814. Dos días después recibió las aguas bautismales en la pila de la parroquia de San Pedro el Real. Bautizo breve, solitario, sin regalos -propio de segundón-.

Aquel niño que había de heredar la fortuna más grande de España y consumirla a mayor esplendor y gloria de su nombre tuvo durante toda su existencia la íntima psicología de un desheredado y, quizá por eso, cumpliría con su destino dilapidando el inmenso patrimonio que recibió.

\subsection{El segundón de Osuna}

$\mathrm{Su}$ infancia no fue más que la propia de un segundón de Casa grande. Para el mayorazgo estuvo reservada la educación más esmerada, el culto único de príncipe heredero. A él, por tanto, le estuvo vetada enseñanza tan privilegiada.

Huérfano, como dijimos, en plena juventud, a Mariano le quedó por todo amparo la rígida tutela de su abuela paterna, la Condesa-duquesa de Benavente doña María Josefa Pimentel, a quien se semejaba en muchos rasgos de su carácter. Escribe su biógrafo, el Marqués de Montesa, que ambos -abuela y nieto- se parecían mucho en las facciones (alteradas indudablemente por la respectiva ingratitud de sus edades) y que aún era mayor el parecido psíquico que ambos tenían: acritud de carácter, insolencia, despotismo, capricho...; pero -para ser justos- a la vez que mucha humanidad, generosidad y, en suma, gran corazón que también tenían ambos personajes (Marichalar, 1930/1955, p. 51). A "Marianín" -como a ella le gustaba llamarle-, el contacto con su abuela le hacía recordar lo egregio de su estirpe, y los derechos y prerrogativas de una alcurnia que pone sobre todas sus empresas el raudo lema del "Más vale volando" que corona, en cimera, el escudo de las armas de los Pimentel. Estos ensueños van prendiendo en su mente y le hacen pensar que un segundón no es nadie, que las puertas no se le abren fácilmente. Sabe perfectamente que le quedan, como antaño, dos únicos caminos para abrirse paso: la tonsura o la espada. El primero, la carrera eclesiástica, no era el camino más atrayente en esa época; con el liberalismo comienza por entonces la decadencia de una iglesia que va a tener -en los años desamortizadores ya muy próximos- una de sus épocas de mayor declive. El segundo camino, la carrera militar, resultaba más atrayente. De ahí que se dijera con acierto por algunos coetáneos (Lafuente, 1846) que, por entonces, empezaban a faltar obispos y a sobrar generales.

Un Girón no podía vacilar en ese dilema; traían la bravura de casta desde la heroica "hazaña de la Sagra" de la que tomaron nombre para su linaje. Mariano sería, pues, militar... Pero habían pasado ya los tiempos en que un Téllez-Girón habría sido coronel a los diez años. Ahora tenía que empezar por ser soldado. Así que, a 
los 19 años ingresó en la carrera de las armas como cadete de guardias. Esto sucedía el año 1833, el mismo en el que su hermano Pedro, duque de Osuna y tantos otros títulos, le cedía el marquesado de la ciudad de Terranova, con pingües propiedades anejas en Italia.

Viéndose así provisto y pertrechado, el 5 de octubre de aquel mismo 1833, su anciana abuela y tutora doña María Josefa Pimentel cedió, por fin, ante la muerte, cuando contaba con 82 años -era la primera cesión de tal señora, "por tratarse de quien se trataba" (Marichalar, 1930/1955, p. 55)-.

Escasos días antes había fallecido también el rey Fernando VII y, precisamente, uno de los primeros servicios que Mariano Téllez-Girón prestaba fue dar escolta al féretro real en su funeral, desde que el 27 de febrero anterior había obtenido la banderola de cadete supernumerario de la segunda brigada del primer escuadrón del Cuerpo de Guardias de su Majestad.

Pero su verdadero campo de operaciones iba a estar en el norte peninsular, una vez iniciada la guerra civil que estalla tras la muerte del monarca. En ella Mariano Terranova abrazó la causa de la reina-niña doña Isabel contra los intereses del pretendiente don Carlos María Isidro. Y sería en las campañas de esta denominada por la historiografía primera Guerra Carlista, donde Mariano Terranova iba a empezar a brillar con luz propia, agregado con su escuadrón al Ejército del Norte, un brillo personal que no tendrá parangón con el que, más tarde, le brindará la diplomacia.

Como los de su sangre, el segundón de la Casa de Osuna encontraba su verdadero camino en las batallas. Había dado con su verdadera vocación, el camino de las armas, "que es, sin disputa en el día -como él mismo escribía por entonces-el mejor y más honorífico". Dirigía las tropas cristinas (de la reina Gobernadora) el general Luis Fernández de Córdova, y Mariano Téllez-Girón fue destinado como su ayudante de campo a fines de 1835. Dice su biógrafo, el Marqués de Montesa, que figurar en la escolta de quien lleva el apellido del famoso Gran Capitán -por Fernández de Córdoba- "no era, ciertamente, para caracolear el caballo y ondear el plumón en desfiles y paradas" (Marichalar, 1930/1955, p. 63). El general Fernández de Córdova tenía preparadas grandes empresas. Y en todas ellas se va a encontrar el segundón de Osuna con un comportamiento heroico: Murguía, el valle de Lodosa, Guevara, Arlabán, Adana, San Adrián, Zubiri... son acciones en las que se distinguió, siendo condecorado el 4 de julio de 1836 sobre el campo de batalla -por mérito contraídos en esa última acción- con la Cruz de San Fernando de primera clase.

Tras una tregua, en la que la reina María Cristina le concede la merced del hábito de caballero de la orden de Calatrava en el mes de noviembre del mismo año, Mariano se reincorpora al Ejército del Norte en 1837 -que para entonces ya mandaba el general Espartero-, hallándose en las operaciones que se sucedieron en Zornoza, Durango y Elorrio, como en la capitulación de la plaza de Irún después de 36 horas de durísimo asedio. En esta acción ganó una nueva Cruz de San Fernando 
de primera clase, y éste no iba a ser su último galardón ni aquélla su última acción. A ella seguirían las de Urnieta, Santa Cruz de Arazo, Lecumberri y otras, hasta que en junio del mismo 1837 marcha con el cuartel general del ejército expedicionario que fue a Aragón a luchar contra las tropas carlistas. Allí hizo toda la campaña, a la que siguió la de Cuenca, la defensa de Madrid y las restantes operaciones que se sucedieron hasta que el pretendiente a la Corona se reintegró a las provincias del Norte.

Para entonces, Mariano Téllez-Girón y Beaufort-Spontin se hallaba muy debilitado de salud. En dos años de dura campaña peleó bravamente, dejando digno su nombre y dejando también su cuerpo marcado de heridas de guerra como buena muestra de ello. Los suyos temen por su quebrantada salud y le obligaron a pedir real licencia para restablecerse. Así, en enero de 1838 le concede la Reina el empleo de Exento Supernumerario de Guardias Reales. Marcha un tiempo a París y, poco después, se le nombra caballero agregado militar en la Embajada extraordinaria designada para la coronación de la reina Victoria, asistiendo en Londres a tan magno acontecimiento. En estos viajes y esta embajada aprendería muchas cosas que después aplicaría en sus estancias por las más importantes cortes europeas.

De vuelta a la Península, Mariano Terranova prestó servicios como gentilhombre de Cámara de su Majestad la Reina desde junio de 1838 en que recibió la llave. Extinguido en 1941 el cuerpo de Guardias, fue destinado entonces al regimiento de Lusitania "en clase de capitán, grado de comandante y distintivo de coronel", según la complicada simultaneidad jerárquica de entonces. A finales de ese mismo año era ya coronel efectivo de caballería y, una tras otra, iban colgando en su pecho la blanca cruz de Malta, una más de San Fernando, la medalla de los distinguidos en el asalto de Irún y la placa de Nuestra Señora de Villaviciosa (que le concedió la reina de Portugal en 1840).

Pese a ello, Mariano Téllez Girón comienza a cambiar su mentalidad. Sus viajes al extranjero -fundamentalmente a Francia, Inglaterra y Bélgica- le han enseñado que hay otra existencia alejada de las habituales. Vestir el uniforme militar y colgarse sobre él las numerosas cruces con las que ha sido condecorado podían esperar a otro momento. Se disponía a "correr mundo", el gran mundo que ofrece la Europa de mediados del siglo XIX.

Pero entonces, el destino le va a brindar lo que más pudo ambicionar en la tierra, pero a cambio de raptarle el único cariño verdadero del momento y del devenir. Su querido hermano Pedro de Alcántara, el primogénito y propietario de la Casa de Osuna, muere inesperadamente.

\subsection{El nuevo Duque}

Por tan luctuoso suceso, aquel 29 de agosto de 1844 Mariano pasa a ser todo lo que, a sus ojos y en su ámbito, se podía llegar a ser en este mundo. Recibe la 
corona ducal de Osuna con todos sus honores, prerrogativas y patrimonio. Era conocido popularmente que los Osuna podían cruzar media España casi sin salir de sus tierras, y que tenían escuadra propia en el Mediterráneo. En el nuevo duque vinieron a reunirse las mayores riquezas y honores, los más ricos mayorazgos de las más principales y antiguas Casas, no solo de España sino también de Bélgica e Italia. Unos mayorazgos que por entonces, cuando él recibe el patrimonio, acababan de quedar desvinculados al entrar en vigor en nuestro país la Ley de abolición de Vínculos y Mayorazgos. Esto le va a permitir hacer uso de ese envidiable patrimonio como bienes de libre disposición, zafados ya de la traba jurídica que -hasta ahora y desde la Edad Media- impusieron los mayorazgos.

Son harto conocidos los títulos en los que sucedió: XI Duque de Osuna, XVI de Gandía, XV de Béjar, XII de Lerma, XV de Arcos, XV del Infantado, XIV de Medina de Rioseco, XVII Conde y XIV Duque de Benavente, entre otros muchos ${ }^{2}$, ocho veces Grande de España de primera clase. Y son igualmente conocidos los palacios que hereda, todos ellos rodeados de inmensas propiedades: el del Infantado en Guadalajara, el de Beauraing en Bélgica (que databa del siglo XIII y que él mandó reconstruir por entero pues lo había derruido la revolución -se trata del mismo palacio en el que acabarán sus días y que, poco después, se incendiaría misteriosamente-), el de los Mendoza en Toledo (luego Hospital de Santa Cruz), el de Arcos en Sevilla, y los de Osuna, Gandía, Béjar, Manzanares, Pastrana, entre otros. También son conocidos los castillos de Peñafiel, Arjona, Mairena, Calahorra, Morón, etc. Sólo en Madrid tenía, además de la finca de Aranjuez y de su maravillosa Alameda -"El Capricho" de su abuela- varias mansiones regias como el Palacio de la calle Leganitos (más tarde convertido en convento), el de la Cuesta de la Vega de los Benavente (luego Embajada de Francia) y el de las Vistillas -donde el nuevo duque Mariano se instaló-, de una magnificencia y fastuosidad encomiables: tapices, reposteros, lienzos, esculturas, armas, arañas, muebles riquísimos... llenaban el palacio. Tiziano, Tintoretto, Rubens, Teniers, Carreño, Sánchez Coello, Van Dyck,

2 También Duque de Plasencia, de Mandas y Villanueva, de Monteagudo, de Estremera, de Francavilla y de Cea, Marqués de Santillana, de Tavara y del Cenete, Príncipe de Éboli y de Squilace, Conde y Príncipe de Melito, 12 veces Grande de España, Marqués de Peñafiel, de Gibraleón, de Terranova, de Zahara, de Argüeso, de Almenara, de Algecilla, de Lombay, de Quirra, de Marchini, de Campoó, de Diano y de Villagarcía, Marqués y Señor de Nules, Conde de Ureña, del Real de Manzanares, de Saldaña, del Cid o Jadraque, de Villada, de Melgar, de Bañares, de Belalcázar, de Oliva, de Mayalde, de Bailén, de Casares, de La Chamusca, de Aliciano, de Centellas, de Simari, de Mayorga, de Osilo, de Coguinas y de Fontanar; primer Conde del reino de Valencia, Vizconde de la Puebla de Alcocer, justicia mayor de Castilla, gran justicier del Reino de Nápoles, primera voz del brazo militar del reino de Cerdeña, almirante de Castilla, merino mayor de Asturias y León, notario mayor de Castilla, camarero mayor del Rey y gentilhombre de Cámara de S. M.; señor de todos los mayorazgos, con sus ciudades, villas, lugares, juros, heredamientos, castillos, baronías, oficios, patronatos, etc., de las Casas de los Girones y Téllez, Mendoza, Lasso de la Vega, Luna, Cisneros, Albornoz, Manzanedo, Sandoval, Enríquez, Toledo, Borja, Centelles, Vigil de Quiñones, Silva, Zúñiga, Ponce de León, Alfonso-Pimentel, Sotomayor, Maza de Lizana, etc. 
Pantoja, Ribera, Esteve, Goya, Pérez Villamil, Legrip, Perich... colgaban allí sus obras. Albergaba también aquel palacio en algunas de sus dependencias la famosa biblioteca de la Casa ducal, con más de 60.000 volúmenes, y una rica colección de manuscritos. Su Archivo familiar también era muy rico.

De la riqueza de esta Casa nobiliaria dice bastante el dato constatado de que tan solo la ciudad de Osuna proporcionara algunos años un millón de fanegas de trigo. Baste saber que Mariano Osuna heredó unas rentas de más de 5 millones de pesetas. Es obvio que nada significan estas cuantiosas cifras de sus rentas los 12 millones de reales que recibió atesorados en oro; ni nada significarían la extensión y calidad de sus fincas, castillos y palacios, objetos artísticos, etc. si no se tiene en cuenta la diferencia de valor del dinero desde hace casi siglo y medio. Todavía un año antes de morir hallaría un crédito de 50 millones de pesetas.

Y Mariano se ciñe su corona ducal coincidiendo con la época de cambios transcendentales que trajo consigo el liberalismo. Decía Donoso Cortés en 1836, al respecto de esos cambios: "la sociedad española está fuera de su asiento"; y algo similar repetiría más adelante Bravo Murillo refiriéndose a la España de mediados del XIX. La revolución liberal había roto con la división estamental de la sociedad; desde ahora los distintos grupos sociales pueden subir o bajar. El dinero es fundamental para elevarse dentro de la sociedad; proporciona prestigio y poder político. Las cosas ya no valen por lo que son sino por lo que representan, como demuestra nuestra literatura romántica, llena de pasajes en tal sentido. Según recoge Marichalar en su biografía del duque, en aquella España del siglo XIX los recibidores de las casas se convierten en lugares suntuosos para esconder, tras de sí, míseras dependencias. Se recubren las mesas con tapetes, las sillas llevan flecos y borlones para tapar las patas, y no precisamente por pudor sino para ocultar la madera de pino cepillada. El terciopelo cede al peluche y el bronce a la calamina. ¿Qué mejor escenario que éste para asistir al drama del delirio y grandeza de un "grande entre los Grandes de España"?

Mariano Osuna era un auténtico diamante dentro de un volquete de escombros. Y él lo sabía. Le gustaba ser quien era. No se cambiaría por nadie. Sabía que la verdadera dignidad de un hombre está en lo que se es, no en lo que se tiene. Y él era "Osuna", nada menos. La vanidad está en distinguirse. Solo un duque de Gandía -antepasado suyo- cuando iba para santo se despoja de todos sus títulos y empieza a firmar "Francisco, pecador".

En 1845, al año de heredar la Casa de Osuna y todas sus agregadas, se le concede la Gran Cruz de Carlos III. Y a fines de ese mismo año recibirá su bautismo político al elegirlo la provincia de Zamora como diputado para el Congreso. En marzo de 1846 se cubrió con el manto de Grande de España como Conde-Duque de Benavente, en presencia de la propia reina Isabel II y apadrinado por el Duque de Frías, Bernardino Fernández de Velasco -el mismo que 16 años antes había apadrinado a su hermano 


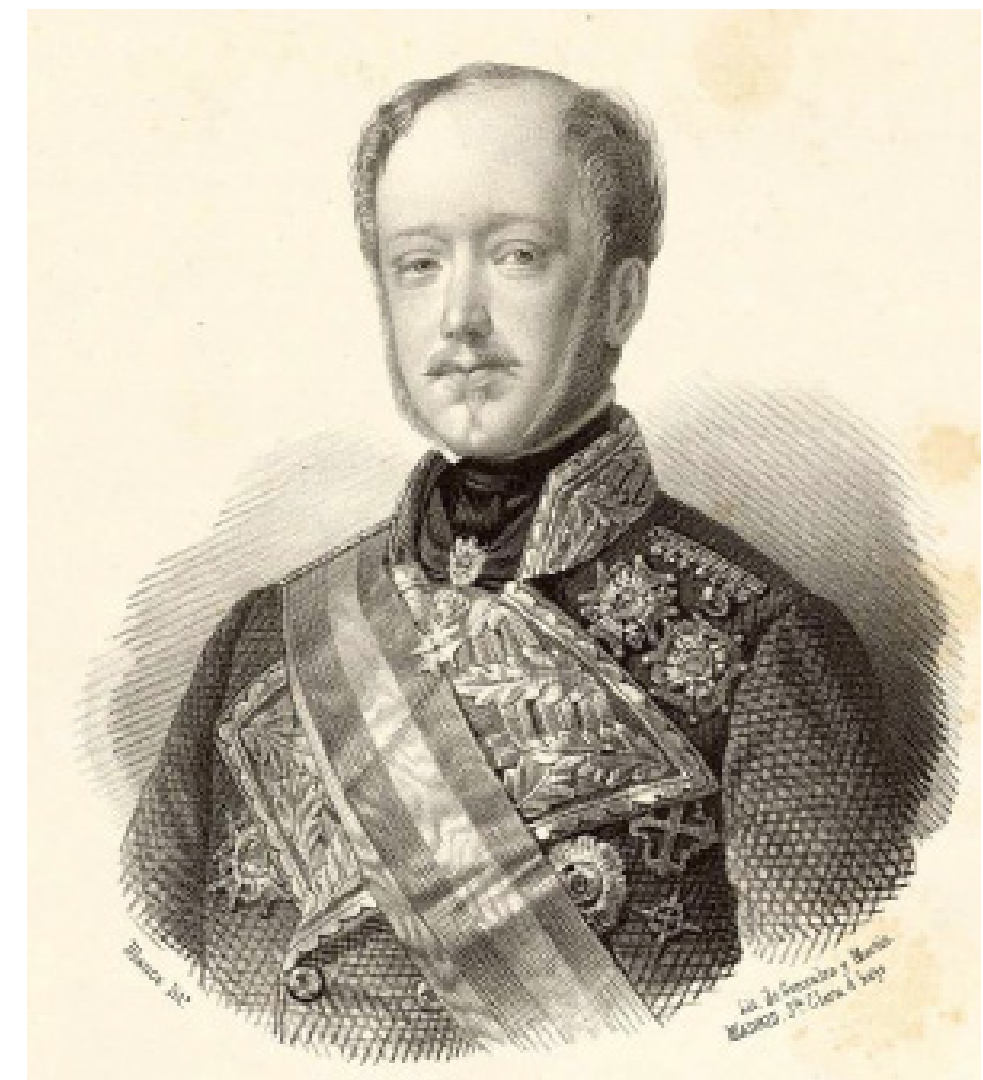

Figura 2. Mariano Téllez-Girón, XII Duque de Osuna

mayor, el malogrado Pedro de Alcántara-. Pocos meses después de convertirse en Grande de España, fue designado senador por derecho propio.

Aparte de su carrera política -terreno que nunca le gustó especialmente-, Mariano Téllez-Girón destacó como ejemplar único de espléndido mecenas, correspondiendo con magnificencia al homenaje de artistas, músicos y literatos. Siendo ya Académico de Honor de la Academia de Nobles Artes de San Fernando, en febrero de 1848 fue elegido numerario de la Academia de la Historia. Algo más tarde será nombrado también presidente de honor del Instituto de África.

Como militar fue ascendido a brigadier de Caballería el $1^{\circ}$ de mayo de 1848 , y a mariscal de Campo el 28 de junio de 1852. 


\subsection{La forja de su leyenda}

Cuatro meses después va a iniciar su carrera diplomática, campo en el que tenía el inicial antecedente ya referido de su estancia en Londres cuando la coronación de la reina Victoria, y campo en el que brillaría con luz propia, un brillo radiante que llegó a encandilar a todas las cortes europeas.

También iba a ser en esta ocasión Londres su lugar de destino, al ser designado el 28 de octubre de 1852 representante de su soberana y de su nación en los funerales de lord Wellington, el llamado "Duque de hierro", sin duda uno de los más célebres militares de todos los tiempos. Y precisamente en Londres comenzaron los destellos del duque Mariano: Osuna va ya como quien es, realizando íntegra la misión a su gasto. Y la gente empezó a oír hablar de alarde en el boato, de lujo inusitado, del buen afecto producido por quien representaba a su patria, y de magníficos regalos. Aquello venía a ser la primera piedra de su leyenda. De vuelta a Madrid, en febrero de 1853 es designado vicepresidente del Senado ${ }^{3}$.

La segunda piedra de esa leyenda la iba a poner en París. En los primeros días de 1853 asistió en el Salón de mariscales de las Tullerías al matrimonio del emperador Napoleón III con la Condesa de Teba, la famosa doña Eugenia de Montijo. El duque de Osuna, de empaque solemne, firmó después de la familia Imperial y de los Cardenales franceses, como el primero de los testigos españoles designado por su Majestad la reina Isabel II.

Pero sería en Rusia, en la corte de los zares, donde estalla -en palabras de su biógrafo Marichalar- el delirio de grandeza del Duque de Osuna. Allí encontrará el monarca más absoluto, el mayor Imperio, el poderío máximo, la campana más grande, el cañón de mayor calibre...; allí se fraguaría, como en ningún otro sitio, su leyenda; allí se titularía el "Grande de los Grandes de España"; y allí será también donde Osuna más reluzca y brille. Todo parecía insinuar, ya pasado el ecuador del siglo XIX, que Rusia accedería en breve a restablecer las relaciones diplomáticas con España, rotas tras la muerte de Fernando VII por la actitud del Gobierno Imperial de Nicolás I que le hizo inclinarse por la causa de Carlos María Isidro durante nuestra guerra civil. En octubre de 1856 dos cartas de Alejandro II -anunciando su advenimiento al trono zarista- son entregadas a la reina española. En contestación cree el Gobierno oportuno designar al Duque de Osuna como portador de la respuesta de la reina española, y al mes siguiente se le nombra Enviado extraordinario y Ministro Plenipotenciario cerca del Zar de todas las Rusias.

¿Quién mejor que Osuna podía dejar más alto el pabellón español?, ¿quién iba a reflejar mayor grandeza que "el grande los Grandes"? y, ¿quién, sino él, iba a salirle más rentable a las arcas de la Monarquía?

3 Archivo del Senado, leg. 326 n $^{\circ} 1$ (4): carta de aceptación del cargo, por parte del duque, dirigida al presidente de la Cámara alta. 
Mariano jamás había cobrado sueldo. Ni como cadete de guardias -pues hizo donación de todos sus haberes a la enfermería del Cuerpo-, ni como militar de graduación, ni como diplomático aceptó jamás los emolumentos y las pensiones que le correspondían. En esta ocasión no iba a ser menos y, renunciando a los 25.000 duros de gajes y 90 reales por legua de camino que le habían sido asignados, aceptó la tarea diplomática que se le había encomendado.

El ministro plenipotenciario ante el Zar de las Rusias llevaba en la misión, como ayudante, al coronel Quiñones de León y, como secretario, al entonces novel escritor Juan Valera, dedicado por esos años a hacer carrera diplomática. Y a través de este, conocemos las peripecias del viaje de Osuna hasta San Petersburgo, las anécdotas que se sucedieron y los agasajos que recibieron en los distintos lugares de Europa donde hicieron escala hasta llegar a su destino (Valera, 1950).

El 15 de diciembre de 1856 el Duque de Osuna presentaba con toda solemnidad, en Tzarscoiselo, al zar Alejandro II las cartas de la reina de España, con las que muy pronto se renovaban las relaciones diplomáticas entre los dos países. E inmediatamente Mariano Osuna pasa a convertirse en el elemento más atrayente de la corte rusa; según Marichalar, en el "niño mimado" de la corte del zar.

El duque no cesa en atenciones y obsequios. No formula el zar un deseo que Osuna no satisfaga en el acto. Alejandro II le distingue con la Gran Cruz de San Alejandro Newski guarnecida de brillantes "en prueba de su amistad personal". A ella sigue el Gran Cordón de la Orden de San Andrés, e incluso le da trato de Embajador pese a que, hasta 1860, no se le otorga esa categoría en España.

Osuna brilla como el sol por entre los astros mayores. En tierra de príncipes él hace valer sus principados. No puede ser menos. Le agasaja la corte por ser quién es, más que por la representación que ostenta. Y con esa corte que le agasaja, en la Rusia de los zares se hallará más que satisfecho. Por eso, prolonga su misión y deja que se conspire a su favor para no ser sustituido. De ahí que escribiera su biógrafo, el reiterado Marqués de Montesa: "Este gran figurón ha encontrado -en Rusia- el retablo apropiado" (Marichalar, 1930/1955, p. 187).

Un día primero de año -emulando a su antepasado, el gran Duque de Osunadon Mariano envía magníficos abanicos antiguos a las señoras de la corte y del cuerpo diplomático rusos; regala a las damas maravillosas flores a diario, claveles de su tierra sevillana, orquídeas de Valencia y Niza...; asombra a los cosacos con fastuosas y opíparas fiestas, diciéndose -lo dicen Valera (1958) y el gran genealogista, contemporáneo suyo, Francisco Fernández de Bethencourt (1908)- que, en una de ellas, terminada la cena, el duque hace arrojar "sus vajillas de oro a las profundidades del río Neva, para asombro de sus convidados" (Marichalar, 1930/1955, p. 132). El hecho es muy dudoso; sin embargo, por entonces -e incluso antes- empiezan a propagarse en Madrid los rasgos inauditos de esplendidez que, fuera de su patria, prodigaba el duque de Osuna. 
Desfigurando su figura real, esos atributos que se le garantizan forjan el mito y la leyenda. Por eso nos dice el propio biógrafo que "aunque no sea cierto mucho de lo que de él se cuenta, es auténtico, porque origina eficazmente el mito y basta a crearlo", al tiempo que nos recuerda aquella aserción de Giovanni Papini: "La leyenda no está corroborada por ningún texto..., pero es verdadera, con una verdad más tremenda que la histórica" (Marichalar, 1930/1955, p. 111). Otros, en cambio, ven al duque como paradigma de "realidad hecha leyenda" (Ramírez, 2014).

Verdadera o no, en la leyenda de Osuna es que además hablan los textos. Existen testimonios auténticos de que en todos sus palacios se servía diariamente la comida, aunque él no estuviese, y que su carruaje bajaba también a diario a la estación a esperarle y recogerle, aún a sabiendas de que el Duque se hallaba muy lejos y no vendría.

Osuna, en sus palacios, brinda el derecho de asilo haciendo que se coma o se baile en tanto él queda retirado. Viaja siempre en tren especial y cuenta con una flota de ellos para prestarle los oportunos servicios allí donde se halle -en unos casos para traer a un cazador de osos asturiano o a un rebaño de merinas con sus pastores, o para buscarle una corbata u ofrecer flores de su tierra, en otros-. E incluso dice su leyenda que algún que otro día que, en el momento de regresar se olvidó de algo, envió a su mayordomo a buscarlo en otro tren análogo.

Y donde más brilló, más brilla su leyenda. A este respecto nos dice el propio Marqués de Montesa que un día, estando Osuna en la corte rusa, se habla de un zorro azul recién aparecido en remota comarca siberiana. Era difícil darle alcance. Pocos, salvo los de su especie, llamaban la atención por su finísima y rara pelambre. Alejandro II quiere lograr los ejemplares que halla y envía una costosa expedición con los más avezados cazadores. Pasa el tiempo, y, tras no pocos esfuerzos, regresan con las pieles precisas para que el peletero de la Casa Imperial pueda confeccionar una pequeña talma -o especie de esclavina- que el zar regala a la zarina. Entre tanto, el duque de Osuna ha enviado, a su costa, otra análoga expedición a Siberia y, tan pronto como regresa, manda que con las pieles conseguidas hagan a su cochero y a su lacayo sendas pellizas (Marichalar, 1930/1955, p. 128).

Y sigue el biógrafo la leyenda y refiere cómo el diplomático conde y luego príncipe Orloff poseía una magnífica yeguada obtenida con el cruce de caballos árabes y daneses muy famosos por lo veloces que eran. El más preciado de ellos se le antoja al duque de Osuna y nos cuenta Marichalar, al respecto, en su agradable prosa:

"Su dueño no lo vende a ningún precio. Osuna puja. Orloff rechaza las ofertas; más, en ausencia suya, cierra el trato la condesa. A la vuelta del conde, éste reclama su caballo. Mas ya no está en cuadra. Pasó a la de Osuna... Orloff va a ver al duque. Pretende deshacer la venta.

— Lo siento —dice Osuna-; el caballo está prestando servicios.

Y se lo muestra allí, enganchado a una noria con la cola y las crines cercenadas. A los caballos de su casa, en cambio, los hacía "herrar de plata 
y clavos de diamantes", según aseguraba el pueblo madrileño" (Marichalar, 1930/1955, p. 144).

Caballero español, el "Grande de los Grandes de España" quiebra lanzas por las estepas eslavas. Y sigue el Marqués de Montesa con su leyenda y nos narra, entre otras, aquella en que Osuna a toda prisa va al Palacio de Invierno en San Petersburgo. El zar está en su trono rodeado del cuerpo diplomático. La sesión es a puerta cerrada y ha dado comienzo. Osuna se desliza sigiloso, enojado, no encuentra taburete y, despojándose de su capa de piel la enrolla y la utiliza para sentarse. Terminada la reunión, cuando a la salida un ujier le trae la capa enjoyada que él había abandonado en el suelo, Osuna la rechaza diciendo que "un Embajador de España no acostumbra a llevarse los asientos" (Marichalar, 1930/1955, p. 185).

Leyenda o realidad... Cierto es que el hecho histórico no corresponde en la mayoría de las veces con lo que la leyenda quiere. Pero, en este caso, ¿qué importa? El mito ha de dar pasto a la leyenda, como la verdad a la historia. Y si Mariano Osuna no hizo todo lo que de él dicen, sí provocó que eso se dijera.

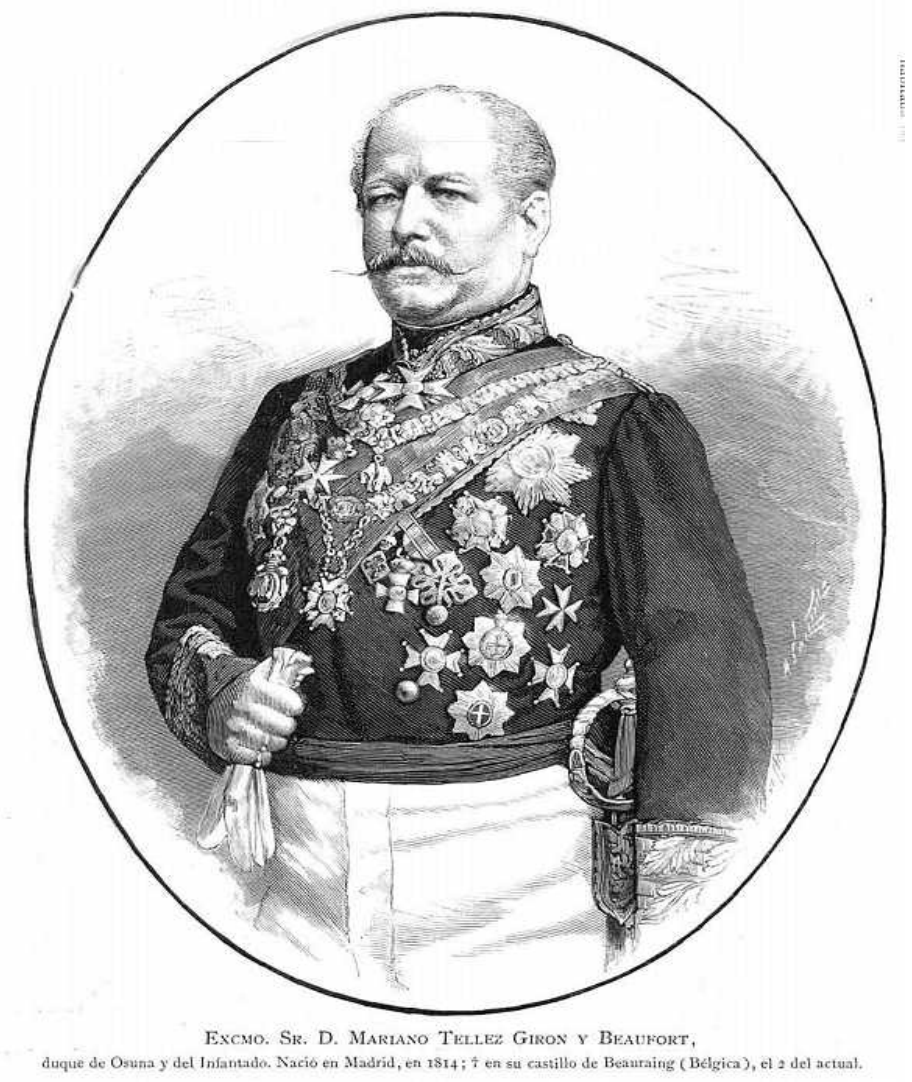

Figura 3. El duque Mariano Téllez-Girón al final de su vida 


\section{4. Últimos servicios a la Monarquía}

Pero la diplomacia expira y en la primavera de 1861 Mariano Girón, "el Grande de los Grandes", abandona la corte rusa. Se aleja del escenario donde más había brillado. Meses atrás, en uno de sus viajes desde San Petersburgo a Madrid, había recibido el collar de la Orden del Toisón de Oro por orden de la reina Isabel II, siendo el cuarto que recibía ese distintivo entre los de su Casa.

De regreso a la Corte española, en el otoño de ese mismo año de1861 es de nuevo designado para representar a la reina y a la nación en las fiestas que, en Berlín, iban a darse con motivo de la coronación del káiser Guillermo I. Fue tanto aquí también su boato que el rey de Prusia quiso honrarlo entonces creando expresamente el collar de diamantes del Águila Roja y nombrándole primer caballero de la nueva orden.

En 1863 asciende a Teniente General. Ya posee toda clase de distinciones y de grados militares. Se siente digno de su raza y puede sentirse satisfecho. Sin embargo, se encuentra decepcionado -retirado en Bélgica, en su palacio de Beauraing-.

Mariano Osuna fue siempre un solitario. Era amigo ejemplar y correcto, pero difícil de acceder a una intimidad verdadera. Tampoco había encontrado en su vida la mujer que él había buscado. Siente la melancolía y opresión propias de quien vive desamparado de sí mismo. Y pasea su soledad y su neurastenia por los balnearios europeos, entonces tan en boga: Baden-Baden, Spa, Wiesbaden... En este estado de ánimo va a conocer a la joven princesa germánica de Salm-Salm y del Santo Imperio y al poco tiempo, el 29 de enero de 1866, obtuvo real licencia para contraer matrimonio con ella. Casaba, al fin, el duque de Osuna en Wiesbaden el 4 de abril de dicho año con su Alteza Serenísima María Leonor de Salm-Salm, de 24 años. Desde entonces el duque anida su amor en Beauraing, aunque el idilio no duraría mucho pues la princesa nunca se sintió realmente atraída por Mariano y sí por el patrimonio de Osuna.

Sin embargo, en aquellos momentos el patrimonio de la Casa se encontraba muy mermado. Manejaba los estados ducales un Consejo de administración compuesto por cinco financieros, tan reputados algunos de ellos como el conocido ex ministro González Romero. La situación económica se hacía irreversible y ya en los años 60 el célebre Bravo Murillo -apoderado general de la Casa de Osuna por entonces- le ofreció al duque nivelar su fortuna y salvarlo de la ruina a la que paulatinamente se veía abocado "con sólo que moderase sus gastos". Pero Mariano Téllez-Girón se negó a disminuir en nada su tren de vida y su boato. Se niega a ser su ruina. Acude -como siempre había hecho- a todo. Y gasta más cuanto más debe.

Quedar bien es su obsesión y a ello obedece cueste lo que cueste. Tiene que ser así pues teme siempre no haberse desprendido suficientemente. Y se desprende, no solo por respeto humano sino también por temor a que puedan dudar de quién es. El gran señor es un sol, y no vive para él sino para que los demás vivan. Osuna -todo corazón- se dejaba explotar por los amigos, por las mujeres, por los administradores... "Todo bicho viviente le saquea y no hay truhan que no sea generoso y hasta magnífico 
a costa suya", afirma Valera en una de sus cartas (1950, II, p. 88). Como no está dispuesto a engañar tiene que ser él el burlado. Su oficio es perdonar. Y dice, una vez más, el Marqués de Montesa sobre este aspecto de su personalidad: "Impertinente con los grandes, altivo con los rivales, Osuna se deja ganar, en cambio, por los más necesitados..." (Marichalar, 1930/1955, p. 133).

En 1873 es elegido para presidir la comisión de España en la Exposición Universal de Viena. Y Osuna sirve a la República por esta soterrada popularidad que le lleva de la mano. Al año siguiente se produce la entronización del rey Alfonso XII y el duque vuelve a España como vicepresidente del Senado. Pese a todo, Osuna brilla en la Corte su fausto inigualado. Gasta como ninguno con ocasión de las bodas reales. E incluso en julio de 1878, a cinco años de su muerte y ya económicamente agonizante, cede de manera espléndida los grandes terrenos adquiridos para establecer el Colegio de Huérfanos de la Guerra.

¿Dilapidador o desprendido...? Don Mariano, duque de Osuna, vive hasta el final -como Grande que es- con ejercicio y servidumbre. Nadie externamente apreciaría que su situación económica era cada vez menos boyante. Ni siquiera él mismo, que en la administración de sus bienes "dejaba hacer" (Mata, 1989, I, p. 615).

Con motivo de las bodas que el 17 de febrero de 1881 iban a contraer en Berlín, en este caso el príncipe heredero Guillermo -futuro kaiser Guillermo IIcon la princesa Victoria Augusta de Sleswig-Holstein, fue precisamente Osuna el elegido por el monarca Alfonso XII, en calidad de Embajador Extraordinario, para representarle en la ceremonia. Seguía siendo el embajador obligado y, una vez más, también fue a su costa y con todo lujo de carrozas, libreas y lacayos -aun estando prácticamente arruinado-.

Claramente el duque sigue ganando todavía batallas. Tal vez la última batalla. Pues el kaiser, admirado de su personalidad y pomposidad, le retiene algunos días mientras despide a las demás embajadas.

\subsection{Epílogo y balance: la ruina de Osuna}

De regreso de su misión, se establece en su retiro belga de Beauraing, su castillo predilecto (Claes y Van den Steen, 2014). Prefiere no volver a España pues aquí tenía empeñado casi todo su patrimonio. Sus apoderados han hipotecado sus bienes en la Península. Y aquel mismo año de 1881 se hace la emisión de obligaciones, que asciende a 43 millones de pesetas, y en las cuales la firma del duque está puesta con una estampilla suya, concedida en virtud de poderes otorgados con anterioridad a la emisión.

Una vez más Osuna quedó burlado. Se niega a ver la realidad porque nunca ha contado para él. Pero su honor -ya que, ahora, no su fortuna- salía a salvo de las garras de apoderados y acreedores. 
Y en esta soledad y este retiro, el duque que con su esplendidez hizo célebre el nombre de Osuna en el siglo XIX, falleció en Beauraing sin ninguna descendencia el 2 de junio de 1882. Poco tiempo después, misteriosamente, el castillo ardía en llamas sin dejar rastro. Era el fin de una gran raza.

Tras su muerte, lógicamente los acreedores cayeron como buitres sobre los bienes ducales, sucediéndose una serie de interminables pleitos y subastas sobre los palacios, cuadros, joyas, tapices y demás obras de arte que constituía su herencia, como han tratado principalmente Miguel Artola (1986), Josep Fontana (1973), Ignacio Atienza (1984 y 1987), Rafael Mata (1987), Juan A. Carmona (1995 y 2001), Jesús D. López Manjón y Fernando Gutiérrez (2004 y 2005). El patrimonio de los Osuna quedó así repartido, cuando no destruido: sus libros, documentos de Archivo y cuadros fueron vendidos o subastados, algunos de sus palacios derribados, sus títulos rehabilitados por diversos parientes, etc. Pues, con la quiebra de la Casa de Osuna, se formó una Comisión de Obligacionistas que se incautó de todas las propiedades.

La gran Biblioteca de los duques del Infantado -iniciada en la Edad Media por el célebre primer marqués de Santillana-, unida a la de los condes de Benavente y a otros libros de los duques de Osuna, fue comprada en 1886 por el Estado y pasó a formar parte de la Biblioteca Nacional de Madrid. Otro tanto parecido ocurrió con el Archivo de la Casa, que fue incautado por el Estado por sentencia de 1894 y que en septiembre de 1917, ante el riesgo de dispersión que corría la documentación, se depositó en el Archivo Histórico Nacional hasta que, en diciembre de 1927, definitivamente fue

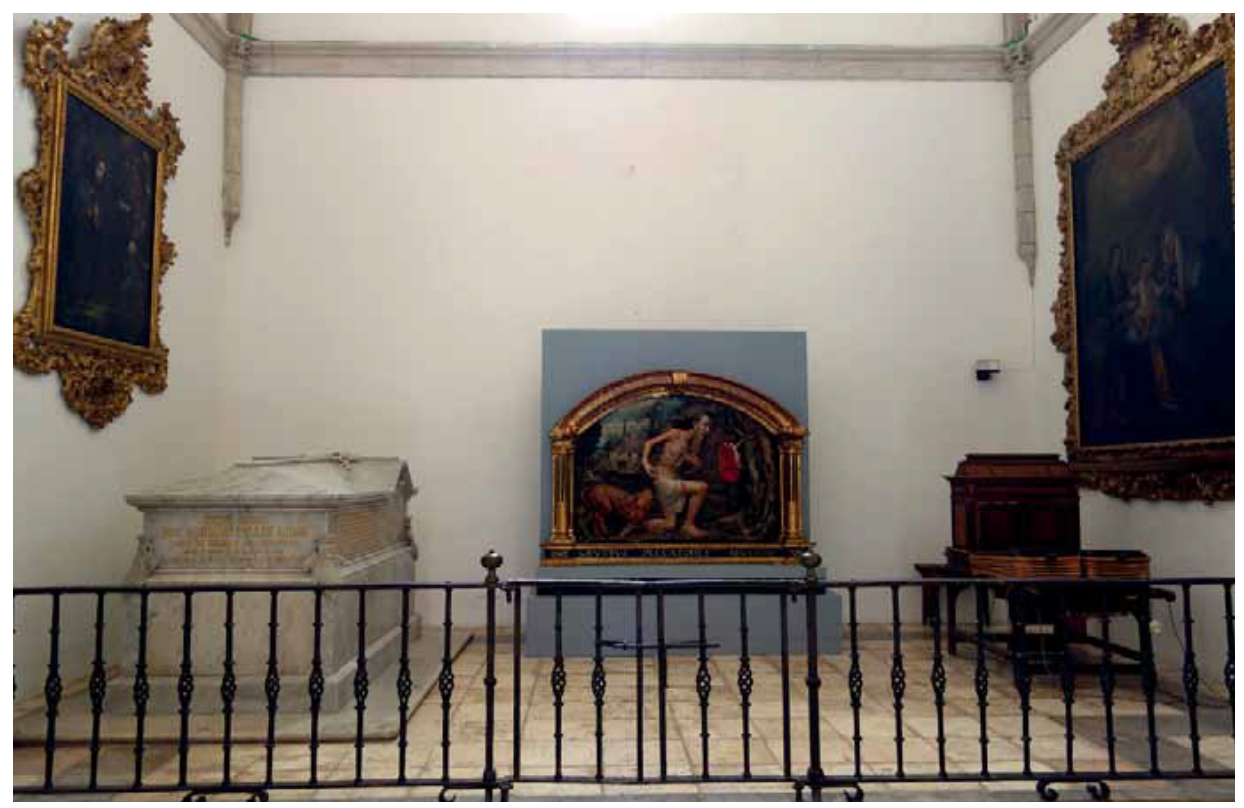

Fig. 4.- Sepulcro del duque Mariano, en mármol de Carrara, obra del escultor suizoJosé Frápolli, en una da las capillas de la Colegiata de Osuna (Foto:José Ma ${ }^{a}$. Rguez. Buzón) 
adquirido por el Estado en propiedad, siendo ésta la razón por la que hoy forme parte del Archivo Histórico de la Nobleza, con sede en el Hospital Tavera de Toledo, constituyendo -la de Osuna- una de sus secciones documentales más importantes.

\section{GONGLUSIONES}

Hemos hecho aquí una revisión de la biografía del noble posiblemente más popular de la España del siglo XIX, en la que buscando la realidad de un personaje mitad hombre y mitad mito - por las luces y sombras que proyectan su vida - se entrelazan sucesos y vivencias que transitan entre lo verdadero y la leyenda.

Sin esperarlo, el segundón de Osuna heredó la mayor fortuna del país, máxime zafado - como quedó- de las rígidas ataduras de los antiguos mayorazgos. Y aprovechó esa enviable herencia para vivir como solo podían hacer muy pocos mortales.

Mariano Téllez-Girón Beaufort-Spontin había jugado en la vida y había perdido. Perdió lo que se jugó, sí, pero había ganado una gloria merecida. Se le ha conocido como despilfarrador, dilapidador o manirroto. Pero muchos se beneficiaron con el dinero que él derrochó y, en primer término, España.

Hoy apenas existe el eco de un nombre que antaño estuvo en boca de muchos.

“„Ni que fuera Osuna!”.

\section{BIBLIOGRAFÍA}

Artola Gallego, Miguel (1986). La Hacienda del siglo XIX. Progresistas y Moderados. Madrid: Alianza Universidad.

Atienza, Julio de (1948). Nobiliario español: diccionario heráldico de apellidos españoles y de títulos nobiliarios. Madrid: Aguilar.

Atienza Hernández, Ignacio (1984). La quiebra de la nobleza castellana en el siglo XVII. Autoridad real y poder señorial: el secuestro de los bienes de la Casa de Osuna. Hispania, 156, pp. 49-81.

Atienza Hernández, Ignacio (1987). Aristocracia, poder y riqueza en la España Moderna. La Casa de Osuna, siglos XV-XIX. Madrid: Siglo XXI.

Atienza Hernández, Ignacio, I.; Mata Olmo, Rafael (1986). La quiebra de la Casa de Osuna. Moneda y Crédito, 176, pp. 71-95.

Bahamonde Magro, Ángel (1986). Crisis de la nobleza de cuna y consolidación burguesa (1840-1880), en L. Otero; A. Bahamonde (eds.), Madrid en la Sociedad del Siglo XXI. Madrid: Consejería de Cultura de la Comunidad de Madrid, vol. 1, pp. 325-376.

Carmona Pidal, Juan Antonio (1995). Las estrategias económicas de la vieja aristocracia española y el cambio agrario en el siglo XIX. Revista de Historia Económica, Año XIII, 1, pp. 63-88. 
Mariano Osuna, entre la realidad y la leyenda - A. Sánchez-González

Carmona Pidal, Juan Antonio (2001). Aristocracia terrateniente y cambio agrario en la EspañadelSigloXIX.LaCasadeAlcañices (1710-1910). Ávila:JuntadeCastillayLeón.

Claes, Marie-Christine y Van en Steen, Christian (2014). Faste et misère: le château de Beauraing au temps d'un Grand d'Espagne (Monographies du TreM.a, $\mathrm{n}^{\circ} 66$ ). Namur: Société Archéologique de Namur.

Clavero Salvador, Bartolomé (1989 [1974]). Mayorazgo, propiedad feudal en Castilla (1369-1836). Madrid: Siglo XXI Editores.

Fernández de Béthencourt, Francisco (1900). Historia genealógica de la Monarquía española, Casa Realy Grandes de España. Madrid: [s.n.] (Enrique Teodoro), tomo II.

Fernández de Córdova, Fernando -Marqués de Mendigorría- (1886). Mis memorias intimas. Madrid: Sucesores de Rivadeneyra, tomo I.

Fontana Lázaro, Josep (1973). Cambio económico y actitudes políticas en la España del siglo XIX. Barcelona: Ariel.

García Carraffa, Alberto y Arturo (1921). Enciclopedia genealógica y heráldica hispanoamericana. Madrid: Imp. Antonio Marzo.

Hernández Montalbán, Francisco J. (1999). La abolición de los señoríos en España, 1811-1837. Valencia: Universitat de València.

Lafuente, Modesto (1846). Teatro Social del siglo XIX. Madrid: D.F. de P. Mellado.

López Manjón, Jesús Damián (2004). Contabilidad señorial en España: Estudio de la Casa Ducal de Osuna desde un enfoque interdisciplinario, tesis inédita de doctorado, Universidad Pablo de Olavide de Sevilla.

López Manjón, Jesús D.; Gutiérrez Hidalgo, Fernando (2005). El uso de los presupuestos en la Casa ducal de Osuna (1860-69). Decomputis: Revista Española de Historia de la Contabilidad, 3, pp. 72-98.

Marichalar, Antonio -Marqués de Montesa- (1959 [1930]). Riesgo y ventura del Duque de Osuna. Madrid: Espasa-Calpe (última ed.: Madrid: Palabra, 1999).

Mata Olmo, Rafael(1987). Ruina nobiliariay enriquecimiento burgués. Nuevos datos sobre la quiebra de la Casa de Osuna. Revista Internacional de Sociología, 45, pp. 149-177.

Mata Olmo, Rafael (1989). Crédito, especulación y trasvase de riqueza en la última etapa de la crisis de la Casa de Osuna. En: Bahamonde Magro, Ángel y Otero Carvajal, Luis Enrique (eds.). La sociedad madrileña durante la Restauración, 1876-1931, Madrid: Comunidad de Madrid, vol. I, pp. 613-636.

Muñoz de Figueroa, Carmen -Condesa de Yebes- (1955). La Condesa-Duquesa de Benavente. Una vida en unas cartas. Madrid: Espasa-Calpe.

Ramírez Olid, José Manuel (2014). "Cuando la realidad se hace leyenda: Mariano Téllez-Girón (1814-1882)", Cuadernos de los Amigos de los Museos de Osuna, Extra 16, pp. 35-43.

Salazar de Castro, Luis (1697). Historia genealógica de la Casa de Lara. 7 vols. Madrid: Imprenta Real. Mateo de Llanos y Guzmán.

Valera, Juan (1950). Cartas desde Rusia. Madrid: Afrodisio Aguado, 2 tomos.

Valera, Juan (1958). Correspondencia. En: Obras completas. Madrid: Aguilar. 